\title{
Identification of plant extracts sensitizing breast cancer cells to TRAIL
}

\author{
SHERIF ABDELHAMED $^{1}$, SATORU YOKOYAMA ${ }^{1}$, LIA HAFIYANI ${ }^{1}$, SURYA K. KALAUNI $^{2}$, \\ YOSHIHIRO HAYAKAWA ${ }^{1}$, SURESH AWALE ${ }^{1,3}$ and IKUO SAIKI ${ }^{1}$ \\ ${ }^{1}$ Division of Pathogenic Biochemistry, Institute of Natural Medicine, University of Toyama, Toyama, \\ Japan; ${ }^{2}$ Central Department of Chemistry, Tribhuvan University, Kirtipur, Kathmandu, Nepal; \\ ${ }^{3}$ Frontier Research Core for Life Sciences, University of Toyama, Toyama, Japan
}

Received November 19, 2012; Accepted January 7, 2013

DOI: $10.3892 /$ or.2013.2293

\begin{abstract}
Triple-negative breast cancer (TNBC) is an aggressive heterogeneous cancer subgroup with a higher rate of distant recurrence and a poorer prognosis compared to other subgroups. Tumor necrosis factor-related apoptosis-inducing ligand (TRAIL) is an attractive molecule that induces cell death in various tumor cells without causing cytotoxicity to normal cells; however, primary or acquired resistance to TRAIL often limits its efficacy in cancer patients. To develop combination therapies to improve TRAIL efficacy and/or to overcome the resistant mechanism, we screened 138 medicinal plant extracts against TRAIL-sensitive and -insensitive TNBC cell lines, MDA-MB-231 and MDA-MB-468. Among them, 5 plant extracts, Uvaria dac, Artemisia vulgaris, Cortia depressa, Dichasia bengalensis and Cinnamomum obtusifolium did not cause apparent cytotoxicity $(<20 \%)$ as a single regimen, but showed significant synergistic effects in combination with TRAIL against both cell lines. Moreover, Uvaria dac, Artemisia vulgaris and Cinnamomum obtusifolium were found to suppress the phosphorylation of p65 that is involved in TRAIL-resistant mechanisms. These observations suggest that the identified plant extracts in combination with TRAIL could lead to potential therapeutic benefits for cancer patients in the clinical setting.
\end{abstract}

\section{Introduction}

Breast cancer is one of the most frequently diagnosed types of cancer and is also the leading cause of cancer-related mortality among women, representing $23 \%$ of total cancer cases and $14 \%$ of cancer-related mortality (1). Breast cancer is classified into different categories according to the expression of three

Correspondence to: Professor Ikuo Saiki, Division of Pathogenic Biochemistry, Institute of Natural Medicine, University of Toyama, 2630 Sugitani, Toyama 930-0194, Japan

E-mail: byosei@inm.u-toyama.ac.jp

Key words: TRAIL, breast cancer cell, medicinal plant extract receptors, estrogen receptor (ER), progesterone receptor (PR), and HER2/Neu (2). A triple-negative breast cancer (TNBC), which is ER-negative, PR-negative, and HER2-negative, is one of the most aggressive forms that accounts for $15-25 \%$ of all breast cancer cases and is associated with a poor prognosis and unresponsiveness to the usual endocrine therapies (3-5).

The tumor necrosis factor-related apoptosis-inducing ligand (TRAIL) is a member of the TNF superfamily that can initiate apoptosis via the activation of death receptor 4 (DR4) and death receptor 5 (DR5). As TRAIL can selectively induce apoptosis in cancer cells, including breast cancer cells, without causing toxicity to normal cells (6-8), it could be a safe medication for cancer patients; however, primary or acquired resistance to TRAIL is often observed which may limit its efficacy in cancer patients (6). Therefore, increasing TRAIL efficacy by combining with natural medicines or other chemotherapeutic agents is an important strategy in the treatment of breast cancer in the clinical setting. We previously identified that vanillin, an active constituent of vanilla, enhances TRAIL-induced apoptosis in cancer cells via suppression of NF- $\mathrm{B}$ (9). This finding prompted us to search for other natural products that can sensitize cancer cells to TRAIL or that can overcome the TRAIL-resistant mechanism.

In the present study, we screened 138 medicinal plant extracts in TNBC cells to identify candidates that are not cytotoxic as a single agent but that can increase TRAIL-induced cytotoxicity synergistically. Among the tested extracts, 5 extracts (Uvaria dac, Artemisia vulgaris, Cortia depressa, Dichasia bengalensis and Cinnamomum obtusifolium) were found to activate TRAIL effects in TRAIL-sensitive TNBC MDA-MB-231 cells and to overcome unresponsiveness in TRAIL-insensitive TNBC MDA-MB-468 cells. We herein report the TRAIL modulatory activity by these identified extracts and their mechanisms of action.

\section{Materials and methods}

Plant extracts and reagents. Plant extracts were dissolved in dimethyl sulfoxide (DMSO) at a concentration of $1,000 \mu \mathrm{g} / \mathrm{ml}$ and these stock solutions were stored at $-20^{\circ} \mathrm{C}$. Recombinant human TRAIL was purchased from PeproTech (Peprotech, London, UK). The plants used in this study are listed in Table I. 
Cell culture. MDA-MB-231, MDA-MB-468, MDA-MB-453 and MCF-7 cells (ATCC, Rockville, MD, USA) were cultured in Dulbecco's modified Eagle's medium (DMEM) supplemented with $10 \%$ heat-inactivated fetal calf serum, $2 \mathrm{mM}$ L-glutamine, $100 \mathrm{U} / \mathrm{ml}$ penicillin, and $10 \mu \mathrm{g} / \mathrm{ml}$ streptomycin. Cells were maintained at $37^{\circ} \mathrm{C}$ in a humidified atmosphere of $5 \% \mathrm{CO}_{2} / 95 \%$ air.

Cell viability assay. Viability of cells following treatment was determined using the WST-1 Cell Counting kit (Wako Pure Chemical Industries, Osaka, Japan) as previously described (10). Briefly, cells were seeded into 96-well plates ( $7 \times 10^{3} / 80 \mu \mathrm{l} /$ well). After $24 \mathrm{~h}, 10 \mu \mathrm{l}$ medium containing each plant extract was added and cells were incubated for an additional $30 \mathrm{~min}$. After the addition of TRAIL (50 ng/ml), cells were incubated for $24 \mathrm{~h}$, and $10 \mu \mathrm{l}$ WST-1 solution was added to each well and incubated at $37^{\circ} \mathrm{C}$ for $1 \mathrm{~h}$. The absorbance at $450 \mathrm{~nm}$ was measured. Relative cell viability was calculated by the formula: Relative cell viability $=$ [average absorbance of experimental wells/average absorbance of control wells]. Synergistic effects were determined when cell viability treated with both TRAIL and plant extract $\left(\mathrm{V}_{\text {comb }}\right)$ was less than predicted additive effects [ $=$ cell viability of TRAIL alone $\left(\mathrm{V}_{\text {TRAIL }}\right) \mathrm{x}$ cell viability of plant extract alone $\left.\left(\mathrm{V}_{\mathrm{ext}}\right)\right]$. The synergy index was calculated by $\mathrm{V}_{\text {com }} /\left(\mathrm{V}_{\text {TRAIL }} \mathrm{x} \mathrm{V}_{\text {ex }}\right)$.

Western blot analysis. Western blot analysis was performed as previously described (11). Cells were seeded and incubated overnight in a $60-\mathrm{mm}$ culture $\operatorname{dish}\left(0.25 \times 10^{6}\right.$ cells $\left./ \mathrm{ml}\right)$. Following treatment, whole cell lysates were collected in lysis buffer [25 mM HEPES pH 7.7, 0.3 M NaCl, $1.5 \mathrm{mM} \mathrm{MgCl} 2,0.2 \mathrm{mM}$ EDTA, $0.1 \%$ Triton X-100, $20 \mathrm{mM} \beta$-glycerophosphate, $1 \mathrm{mM}$ sodium orthovanadate, $1 \mathrm{mM}$ phenylmethylsulfonyl fluoride (PMSF), $1 \mathrm{mM}$ dithiothreitol (DTT), $10 \mathrm{mg} / \mathrm{ml}$ aprotinin and $10 \mathrm{mg} / \mathrm{ml}$ leupeptin]. Equal amounts of protein were resolved by electrophoresis on acrylamide gels. Antibodies against caspase-3, PARP, XIAP, MCL-1 and phosphorylated p65 were purchased from Cell Signaling Technology (Danvers, MA, USA). Antibodies against $\beta$-actin and p65 were purchased from Santa Cruz Biotechnology Inc., (Santa Cruz, CA, USA).

\section{Results}

TRAIL sensitivity in breast cancer cell lines. Since each cell line shows various sensitivities to TRAIL due to different expression levels of BAX, MCL-1, IAPs and others (12-17), we initially tried four breast cancer cell lines, MDA-MB-231, $-468,-453$ and MCF-7, to distinguish TRAIL-sensitive from -insensitive cells. Of note, the cell viability assay showed that only MDA-MB-231 cells were sensitive to TRAIL and the others were insensitive (Fig. 1A and data not shown). Both MDA-MB-231 and MDA-MB-468 are triple-negative (ER', $\mathrm{PR}^{-}$and HER2-) breast cancer cells, and are reported to be the most severe forms of breast cancer (3-5); therefore, we focused on these two cell lines in the present study. Furthermore, cleaved PARP and cleaved caspase-3, which are known as apoptotic markers, were also observed in MDA-MB-231 cells with TRAIL in a time- and concentration-dependent manner, but not in MDA-MB-468 cells (Fig. 1B). This showed that MDA-MB-231 cells are sensitive to TRAIL and MDA-MB-468
A

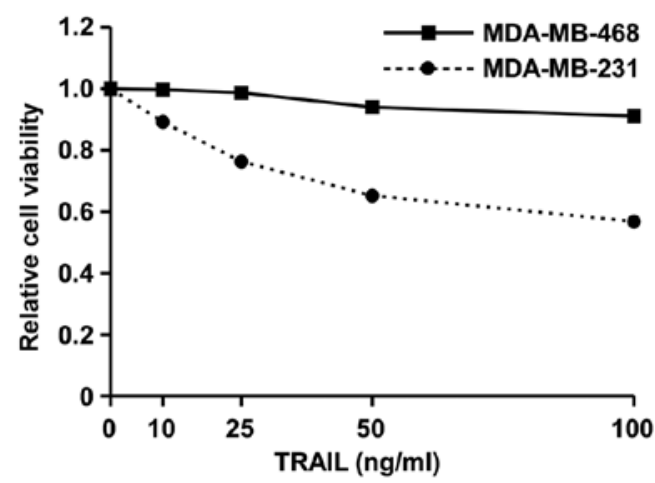

B

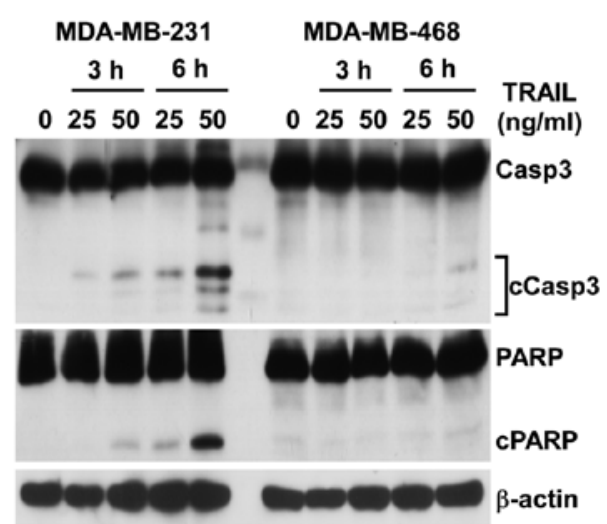

Figure 1. TRAIL sensitivity in breast cancer cell lines. (A) Cell viability assay in MDA-MB-231 and MDA-MB-468 cells. Cells were treated with various concentrations of TRAIL for $24 \mathrm{~h}$. Results are normalized to the vehicle control in each cell line. (B) Expression of cleaved caspase-3 and cleaved PARP in MDA-MB-231 and MDA-MB-468 cells detected by western blot analysis. Cells were treated with the indicated concentrations of TRAIL for the indicated times.

cells are insensitive, and that the cell death induced by TRAIL might be due to apoptosis.

Classification of the plant extracts according to their cytotoxic and/or synergistic effects. Subsequently, we identified the plant extracts that showed less cytotoxicity as a single agent, but that enhanced TRAIL effects in TRAIL-sensitive cells or that overcame unresponsiveness in TRAIL-insensitive cells. One hundred and thirty-eight plant extracts with or without TRAIL were screened by cell viability assay (Fig. 2 and Table I). Two criteria were used to classify the plant extracts; first, we determined whether cell viability treated with the plant extracts alone $\left(\mathrm{V}_{\text {ext }}\right)$ was $>0.8(>80 \%$ cell survival $)$ at the maximum tested concentration of $50 \mu \mathrm{g} / \mathrm{ml}$. Second, we checked whether the combination of plant extract with TRAIL showed a synergistic effect, indicating that the detected cell viability with both TRAIL and plant extract $\left(\mathrm{V}_{\text {comb }}\right)$, is less than its predicted additive effect [= cell viability with TRAIL alone $\left.\left(\mathrm{V}_{\text {TRAIL }}\right) \times \mathrm{V}_{\text {ext }}\right]$ and the synergy index $\left[=\mathrm{V}_{\text {com }} /\left(\mathrm{V}_{\text {TRAIL }}\right.\right.$ $\left.\mathrm{x} \mathrm{V}_{\mathrm{ext}}\right)$ ] is also $<0.8$. In TRAIL-sensitive MDA-MB-231 cells, 100 extracts showed low cytotoxicity $\left(\mathrm{V}_{\mathrm{ext}}>0.8\right)$. Among them, 9 extracts (C.fructus, C. obtusifolium, C. japonica, U. dac, A. vulgaris, C. depressa, D. bengalensis, A. venustum and $P$. benghalensis) showed synergistic effects with TRAIL. In 


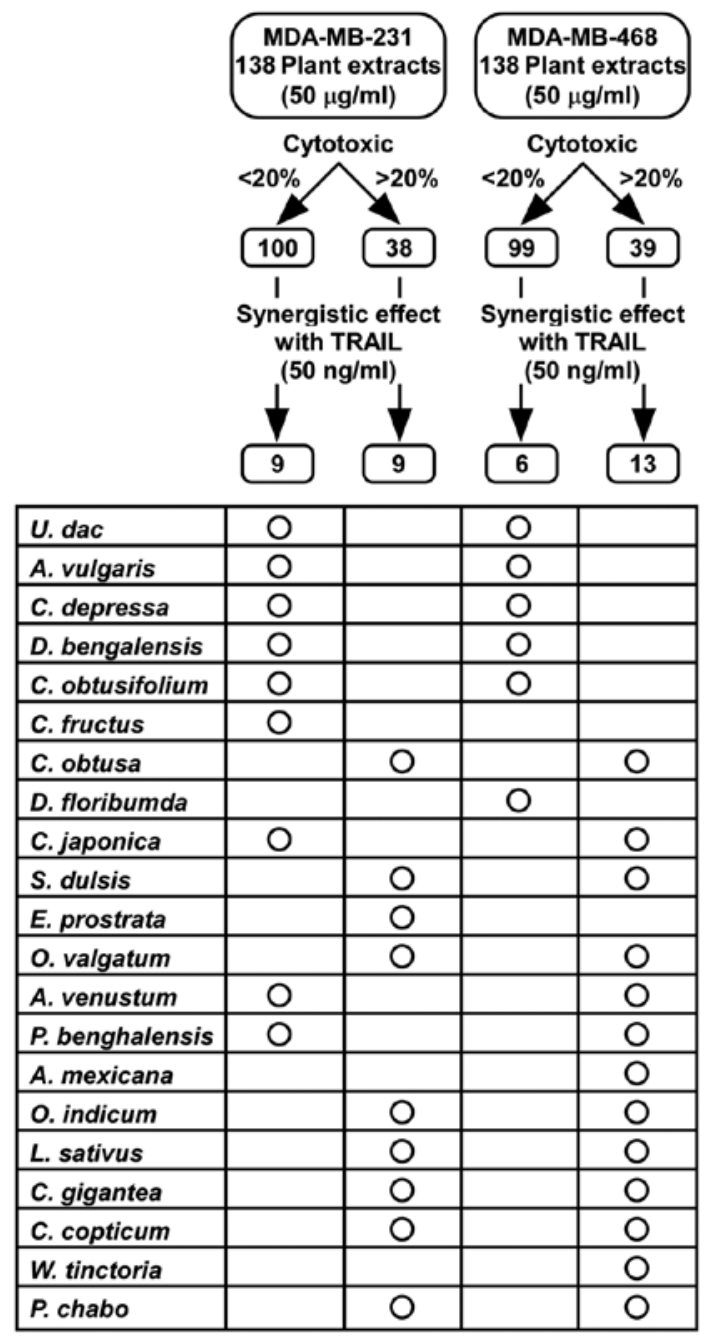

Figure 2. Screening of 138 medicinal plant extracts and identification of 5 plant extracts sensitizing breast cancer cells to TRAIL. The classifications of 138 plant extracts were determined by the cell viability assay in MDA-MB-231 and MDA-MB-468 cells.

the case of MDA-MB-468 cells, 99 extracts showed low cytotoxicity and 6 extracts $(D$. floribumda, C. obtusifolium, U. dac, $A$. vulgaris, $C$. depressa and D. bengalensis) showed synergistic effects with TRAIL. As shown in Fig. 2, only 5 extracts met these two criteria in both cell lines, U. dac, A. vulgaris, C. depressa, D. bengalensis and C. obtusifolium.

Five identified plant extracts induce cell death in a concentration-dependent manner. To check the concentrationdependency of the 5 selected plant extracts, we performed the cell viability assay at various extract concentrations with TRAIL (Fig. 3). These extracts showed synergistic effects with TRAIL in both cell lines in a concentration-dependent manner; therefore, we further examined whether the induced cell death was due to increased apoptosis or due to other types of cell death (Fig. 4). In both cell lines, the cleavage of PARP and caspase-3 was strongly detected when treated with a combination of plant extract and TRAIL compared with TRAIL alone. We then checked the expression and phosphorylation of $\mathrm{p} 65$, in addition to the expression of XIAP and MCL-1, which are involved in TRAIL-resistant mechanisms $(9,12,14-16)$.
A
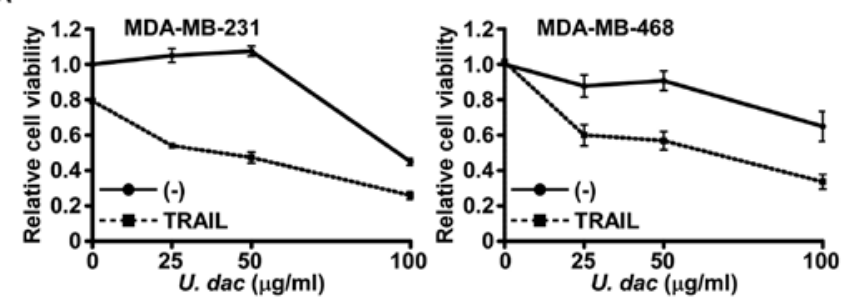

B
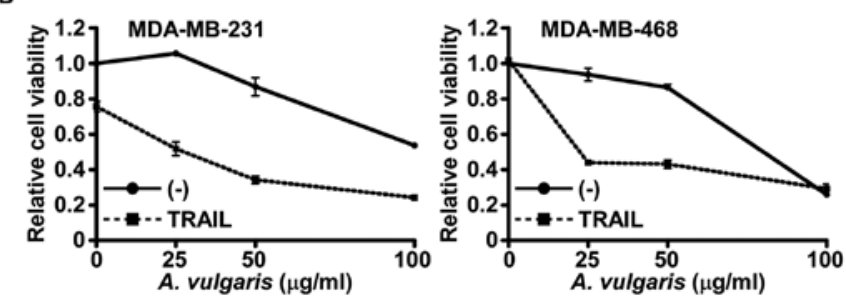

C
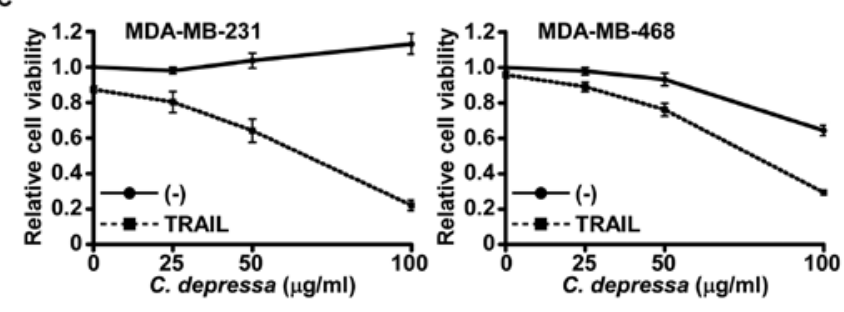

D
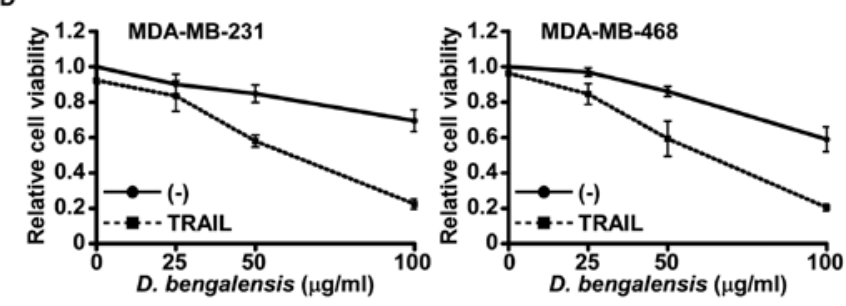

E
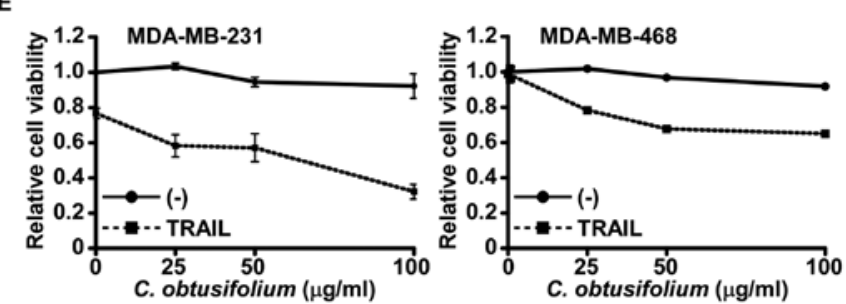

Figure 3. Sensitization of breast cancer cells to TRAIL with the identified plant extracts. (A-E) Cell viability assays in breast cancer cells with TRAIL $(50 \mathrm{ng} / \mathrm{ml})$ and 5 plant extracts. Results are normalized to the vehicle control.

Markedly, the three extracts $(U . d a c, A$. vulgaris and C. obtusifolium) showed clear inhibition of the phosphorylation of p65, suggesting that the reduced phosphorylation of p65 could explain the synergistic effect of $U$. dac, A. vulgaris and $C$. obtusifolium with TRAIL. On the other hand, the two extracts, $C$. depressa and $D$. bengalensis, that also showed synergistic effects with TRAIL did not show the downregulation of MCL-1, XIAP or phosphorylation of p65, suggesting that these two extracts may cause the synergistic effects with TRAIL by affecting different proteins or pathways. 
Table I. Evaluation of 138 plant extracts for their cytotoxicity as a single regimen and/or additive or synergistic effect with TRAIL.

\begin{tabular}{|c|c|c|c|c|c|c|c|c|}
\hline \multirow[t]{3}{*}{ Extract } & \multicolumn{2}{|c|}{ MDA-MB-231 } & \multirow{3}{*}{$\begin{array}{c}\text { Predicted } \\
\text { additive } \\
\text { effect }\end{array}$} & \multirow{3}{*}{$\begin{array}{c}\text { Synergy } \\
\text { Index }\end{array}$} & \multicolumn{2}{|c|}{ MDA-MB-468 } & \multirow{3}{*}{$\begin{array}{c}\text { Predicted } \\
\text { additive } \\
\text { effect }\end{array}$} & \multirow{3}{*}{$\begin{array}{l}\text { Synergy } \\
\text { Index }\end{array}$} \\
\hline & $\begin{array}{c}\text { TRAIL } \\
(-)\end{array}$ & $\begin{array}{c}\text { TRAIL } \\
(+)\end{array}$ & & & $\begin{array}{c}\text { TRAIL } \\
(-)\end{array}$ & $\begin{array}{l}\text { TRAIL } \\
(+)\end{array}$ & & \\
\hline & 1.00 & 0.76 & & & 1.00 & 0.97 & & \\
\hline Zizyphi Fructus & 0.86 & 0.69 & 0.66 & 1.05 & 1.06 & 1.00 & 1.03 & 0.98 \\
\hline Cinnamomi Cortex & 0.88 & 0.59 & 0.67 & 0.88 & 1.06 & 1.04 & 1.03 & 1.01 \\
\hline Rhei Rhizoma & 0.80 & 0.62 & 0.61 & 1.01 & 0.99 & 0.98 & 0.96 & 1.01 \\
\hline Araliae Cordatae Rhizoma & 0.95 & 0.68 & 0.72 & 0.94 & 1.01 & 0.95 & 0.98 & 0.97 \\
\hline Condonopsitis Radix & 0.97 & 0.72 & 0.74 & 0.98 & 0.96 & 0.94 & 0.93 & 1.01 \\
\hline Ginseng Radix Rubra & 1.03 & 0.80 & 0.79 & 1.02 & 0.95 & 0.93 & 0.93 & 1.00 \\
\hline Salviae miltiorrhizae Radix & 1.00 & 0.75 & 0.76 & 0.98 & 1.01 & 1.02 & 0.98 & 1.04 \\
\hline Armeniacae Semen & 0.96 & 0.72 & 0.74 & 0.98 & 1.04 & 1.03 & 1.01 & 1.02 \\
\hline Eucommiae Cortex & 0.89 & 0.61 & 0.68 & 0.89 & 0.99 & 0.94 & 0.96 & 0.98 \\
\hline Zanthoxyli Fructus & 0.99 & 0.65 & 0.76 & 0.86 & 1.00 & 0.95 & 0.97 & 0.98 \\
\hline Acanthopanax senticosus Harms & 1.03 & 0.70 & 0.78 & 0.89 & 1.03 & 1.01 & 1.00 & 1.01 \\
\hline Morus bombycis Koidz & 0.94 & 0.66 & 0.71 & 0.92 & 1.03 & 1.03 & 1.00 & 1.03 \\
\hline Rehmanniae Radix & 1.13 & 0.88 & 0.86 & 1.02 & 1.04 & 1.01 & 1.01 & 1.01 \\
\hline Platycodi Radix & 1.53 & 1.00 & 1.17 & 0.86 & 1.04 & 1.07 & 1.00 & 1.07 \\
\hline Corni Fructus & 1.45 & 0.81 & 1.10 & 0.73 & 0.97 & 1.01 & 0.94 & 1.07 \\
\hline Sparganii Rhizoma & 1.08 & 0.95 & 0.83 & 1.15 & 0.96 & 1.02 & 0.93 & 1.09 \\
\hline Trichosanthis Radix & 1.28 & 1.03 & 0.97 & 1.06 & 0.93 & 0.97 & 0.91 & 1.07 \\
\hline Lycii Cortex & 1.16 & 1.05 & 0.89 & 1.19 & 0.99 & 1.00 & 0.96 & 1.04 \\
\hline Cannabis Fructus & 1.12 & 0.75 & 0.86 & 0.88 & 1.05 & 1.10 & 1.02 & 1.08 \\
\hline Tribuli Fructus & 1.05 & 0.73 & 0.80 & 0.91 & 1.02 & 1.11 & 0.99 & 1.12 \\
\hline Gentianae macrophyllae Radix & 0.97 & 0.64 & 0.74 & 0.86 & 1.02 & 1.04 & 0.99 & 1.05 \\
\hline Puerariae Radix & 1.01 & 0.79 & 0.77 & 1.03 & 1.08 & 1.05 & 1.05 & 1.00 \\
\hline Zingiberis Rhizoma & 0.99 & 0.71 & 0.75 & 0.94 & 0.94 & 0.91 & 0.91 & 1.00 \\
\hline Alismatis Rhizoma & 0.87 & 0.63 & 0.66 & 0.94 & 0.93 & 0.92 & 0.90 & 1.03 \\
\hline Zingiberis Siccatum Rhizoma & 1.10 & 0.78 & 0.84 & 0.93 & 0.94 & 0.96 & 0.91 & 1.05 \\
\hline Sophorae Radix & 1.26 & 0.93 & 0.96 & 0.96 & 1.00 & 1.01 & 0.97 & 1.05 \\
\hline Rehmannia glutinosa & 1.05 & 0.70 & 0.80 & 0.87 & 1.38 & 1.43 & 1.34 & 1.07 \\
\hline Zedoariae Rhizoma & 0.76 & 0.66 & 0.58 & 1.14 & 0.94 & 0.97 & 0.91 & 1.07 \\
\hline Ephedrae Herba & 1.05 & 0.73 & 0.80 & 0.92 & 0.87 & 0.87 & 0.84 & 1.03 \\
\hline Paeoniae Moutan Cortex & 0.93 & 0.65 & 0.71 & 0.91 & 0.99 & 0.94 & 0.96 & 0.98 \\
\hline Evodiae Fructus & 0.93 & 0.66 & 0.71 & 0.93 & 1.05 & 1.11 & 1.02 & 1.09 \\
\hline Paeoniae Radix & 0.78 & 0.91 & 0.60 & 1.52 & 0.88 & 0.88 & 0.86 & 1.03 \\
\hline Arctii Fructus & 0.88 & 0.93 & 0.67 & 1.39 & 0.68 & 0.74 & 0.66 & 1.13 \\
\hline Polygalae Radix & 0.75 & 0.73 & 0.57 & 1.29 & 0.87 & 0.85 & 0.85 & 1.01 \\
\hline Glehniae Radix cum Rhizoma & 0.85 & 0.75 & 0.65 & 1.16 & 0.93 & 0.93 & 0.91 & 1.02 \\
\hline Sinomeni Caulis et Rhizoma & 0.77 & 0.78 & 0.58 & 1.33 & 0.91 & 0.89 & 0.88 & 1.01 \\
\hline Dipsaci Radix & 0.99 & 0.99 & 0.76 & 1.31 & 0.94 & 0.91 & 0.91 & 1.00 \\
\hline Achyranthis Radix & 0.84 & 0.60 & 0.64 & 0.93 & 0.96 & 0.95 & 0.93 & 1.02 \\
\hline Leonuri Herba & 0.89 & 0.77 & 0.68 & 1.14 & 0.94 & 1.18 & 0.91 & 1.29 \\
\hline Woodforidia fruticos $a^{\mathrm{a}}$ & 0.68 & 0.62 & 0.52 & 1.19 & 0.50 & 0.49 & 0.48 & 1.02 \\
\hline Quercus infectoria & 0.48 & 0.47 & 0.37 & 1.26 & 0.41 & 0.34 & 0.40 & 0.86 \\
\hline Gardenia oronaria & 0.77 & 0.60 & 0.59 & 1.02 & 0.82 & 0.76 & 0.80 & 0.96 \\
\hline Penthum Operculina & 0.83 & 0.69 & 0.63 & 1.09 & 0.88 & 0.87 & 0.85 & 1.01 \\
\hline Iris florentia & 0.85 & 0.69 & 0.65 & 1.06 & 0.78 & 0.76 & 0.76 & 1.00 \\
\hline Myrica nagi & 0.82 & 0.76 & 0.63 & 1.21 & 0.82 & 0.83 & 0.79 & 1.05 \\
\hline $\begin{array}{l}\text { Chamaecyparis obtusa } \\
\text { (MeOH Ext., upper layer) }\end{array}$ & 0.18 & 0.17 & 0.14 & 1.24 & 0.24 & 0.27 & 0.24 & 1.13 \\
\hline
\end{tabular}


Table I. Continued.

\begin{tabular}{|c|c|c|c|c|c|c|c|c|}
\hline \multirow[t]{3}{*}{ Extract } & \multicolumn{2}{|c|}{ MDA-MB-231 } & \multirow{3}{*}{$\begin{array}{c}\text { Predicted } \\
\text { additive } \\
\text { effect }\end{array}$} & \multirow{3}{*}{$\begin{array}{l}\text { Synergy } \\
\text { Index }\end{array}$} & \multicolumn{2}{|c|}{ MDA-MB-468 } & \multirow{3}{*}{$\begin{array}{l}\text { Predicted } \\
\text { additive } \\
\text { effect }\end{array}$} & \multirow{3}{*}{$\begin{array}{l}\text { Synergy } \\
\text { Index }\end{array}$} \\
\hline & $\begin{array}{l}\text { TRAIL } \\
(-)\end{array}$ & $\begin{array}{l}\text { TRAIL } \\
(+)\end{array}$ & & & $\begin{array}{l}\text { TRAIL } \\
(-)\end{array}$ & $\begin{array}{l}\text { TRAIL } \\
(+)\end{array}$ & & \\
\hline & 1.00 & 0.76 & & & 1.00 & 0.97 & & \\
\hline $\begin{array}{l}\text { Chamaecyparis obtusa } \\
\text { (MeOH Ext., lower layer) }\end{array}$ & 0.72 & 0.21 & 0.55 & 0.39 & 0.75 & 0.37 & 0.73 & 0.51 \\
\hline Cordyceps sinensis & 0.91 & 0.77 & 0.70 & 1.11 & 1.05 & 0.88 & 1.02 & 0.86 \\
\hline Derris floribumda $\left(\mathrm{CHCl}_{3}\right.$ Ext. $)$ & 0.82 & 0.55 & 0.63 & 0.88 & 0.87 & 0.65 & 0.85 & 0.77 \\
\hline Derris floribumda (MeOH Ext.) & 0.57 & 0.53 & 0.44 & 1.22 & 0.79 & 0.65 & 0.77 & 0.84 \\
\hline Cinnamomum obtusifolium Nees. & 0.89 & 0.39 & 0.68 & 0.58 & 0.97 & 0.68 & 0.94 & 0.72 \\
\hline Cryptomeria japonica & 0.94 & 0.26 & 0.71 & 0.37 & 0.66 & 0.39 & 0.64 & 0.61 \\
\hline Uvaria dac & 1.13 & 0.47 & 0.86 & 0.54 & 1.09 & 0.74 & 1.06 & 0.70 \\
\hline Artemisia vulgaris & 0.87 & 0.34 & 0.66 & 0.52 & 0.93 & 0.35 & 0.90 & 0.39 \\
\hline Scoparia dulsis & 0.54 & 0.12 & 0.41 & 0.30 & 0.57 & 0.36 & 0.56 & 0.65 \\
\hline Unidentified & 1.01 & 0.88 & 0.77 & 1.14 & 0.82 & 0.83 & 0.80 & 1.04 \\
\hline Polygonum barbatum (L.) & 0.92 & 0.88 & 0.70 & 1.26 & 0.81 & 0.78 & 0.79 & 0.99 \\
\hline Euphorbia hirta L. & 0.75 & 0.63 & 0.57 & 1.11 & 0.84 & 0.75 & 0.81 & 0.93 \\
\hline Eclipta prostrata & 0.62 & 0.26 & 0.47 & 0.55 & 0.66 & 0.59 & 0.64 & 0.93 \\
\hline Chinopodium ambrosioides & 1.05 & 0.82 & 0.80 & 1.03 & 0.81 & 0.87 & 0.79 & 1.10 \\
\hline Senna alata & 1.05 & 0.86 & 0.80 & 1.07 & 0.84 & 0.78 & 0.82 & 0.96 \\
\hline Allium wallichii & 0.62 & 0.55 & 0.47 & 1.18 & 0.60 & 0.62 & 0.59 & 1.05 \\
\hline Potentilla peduncularis & 1.10 & 0.84 & 0.84 & 1.00 & 0.67 & 0.77 & 0.65 & 1.18 \\
\hline Cortia depressa & 0.97 & 0.44 & 0.74 & 0.60 & 0.81 & 0.57 & 0.79 & 0.72 \\
\hline Rhododendron campanulatum & 0.85 & 0.97 & 0.65 & 1.49 & 0.78 & 0.77 & 0.76 & 1.02 \\
\hline Rhododendron ciliatum Hook. & 0.90 & 0.75 & 0.69 & 1.09 & 0.81 & 0.79 & 0.79 & 1.00 \\
\hline Primula rotundifolia & 0.93 & 0.77 & 0.71 & 1.09 & 1.17 & 1.06 & 1.13 & 0.93 \\
\hline Boschniakia himalaica & 1.05 & 0.94 & 0.80 & 1.18 & 1.09 & 1.05 & 1.06 & 0.99 \\
\hline Clematis montana & 1.04 & 1.04 & 0.79 & 1.31 & 1.18 & 1.11 & 1.15 & 0.97 \\
\hline Bistorta macrophylla & 1.07 & 1.05 & 0.82 & 1.29 & 1.10 & 1.09 & 1.07 & 1.02 \\
\hline Primula denticulata & 0.90 & 0.90 & 0.69 & 1.30 & 1.08 & 1.02 & 1.05 & 0.98 \\
\hline Ohiglossum valgatum & 0.77 & 0.28 & 0.59 & 0.48 & 0.57 & 0.26 & 0.55 & 0.47 \\
\hline Unidentified & 0.99 & 0.97 & 0.76 & 1.28 & 1.13 & 1.13 & 1.10 & 1.03 \\
\hline Semecarpus anacardium & 0.15 & 0.15 & 0.11 & 1.30 & 0.14 & 0.14 & 0.14 & 1.02 \\
\hline Dichasia bengalensis & 0.82 & 0.42 & 0.63 & 0.67 & 0.81 & 0.37 & 0.79 & 0.47 \\
\hline Senna fistula & 0.97 & 0.93 & 0.74 & 1.25 & 1.25 & 1.10 & 1.21 & 0.91 \\
\hline Euphorbia hirta & 0.97 & 0.86 & 0.74 & 1.16 & 1.17 & 1.04 & 1.14 & 0.91 \\
\hline Curcuma caesia & 0.08 & 0.08 & 0.06 & 1.31 & 0.08 & 0.07 & 0.07 & 1.02 \\
\hline Cedrus deodara & 0.74 & 0.63 & 0.56 & 1.12 & 0.96 & 0.83 & 0.93 & 0.89 \\
\hline Argemonum & 1.10 & 0.72 & 0.84 & 0.86 & 0.94 & 0.79 & 0.91 & 0.87 \\
\hline Chrysenthamum & 0.73 & 0.57 & 0.56 & 1.02 & 0.84 & 0.78 & 0.81 & 0.96 \\
\hline Adiantum venustum & 0.92 & 0.53 & 0.70 & 0.75 & 0.77 & 0.51 & 0.75 & 0.69 \\
\hline Nerium oleander & 0.97 & 0.92 & 0.74 & 1.25 & 1.00 & 0.92 & 0.97 & 0.94 \\
\hline Euphorbia royleana & 0.08 & 0.08 & 0.06 & 1.27 & 0.09 & 0.09 & 0.09 & 1.03 \\
\hline Pogostemon benghalensis & 0.88 & 0.36 & 0.67 & 0.53 & 0.65 & 0.29 & 0.63 & 0.45 \\
\hline Bauhinia variegata & 0.88 & 0.89 & 0.67 & 1.32 & 0.91 & 0.77 & 0.88 & 0.87 \\
\hline Tamarindus indica & 0.59 & 0.58 & 0.45 & 1.28 & 0.64 & 0.57 & 0.62 & 0.92 \\
\hline Woodforidia fruticos $a^{\mathrm{a}}$ & 0.59 & 0.58 & 0.45 & 1.28 & 0.70 & 0.63 & 0.68 & 0.93 \\
\hline Argemone mexicana & 0.72 & 0.56 & 0.55 & 1.03 & 0.51 & 0.39 & 0.50 & 0.80 \\
\hline Ficus lacor & 0.72 & 0.79 & 0.55 & 1.43 & 0.67 & 0.67 & 0.65 & 1.02 \\
\hline Oroxylum indicum & 0.78 & 0.36 & 0.60 & 0.61 & 0.58 & 0.26 & 0.56 & 0.46 \\
\hline Lathyrus sativus & 0.61 & 0.15 & 0.47 & 0.33 & 0.44 & 0.16 & 0.43 & 0.37 \\
\hline Dichroa febrifuga & 0.85 & 0.77 & 0.65 & 1.19 & 0.93 & 0.89 & 0.90 & 0.99 \\
\hline
\end{tabular}


Table I. Continued.

\begin{tabular}{|c|c|c|c|c|c|c|c|c|}
\hline \multirow[t]{3}{*}{ Extract } & \multicolumn{2}{|c|}{ MDA-MB-231 } & \multirow{3}{*}{$\begin{array}{l}\text { Predicted } \\
\text { additive } \\
\text { effect }\end{array}$} & \multirow{3}{*}{$\begin{array}{l}\text { Synergy } \\
\text { Index }\end{array}$} & \multicolumn{2}{|c|}{ MDA-MB-468 } & \multirow{3}{*}{$\begin{array}{l}\text { Predicted } \\
\text { additive } \\
\text { effect }\end{array}$} & \multirow{3}{*}{$\begin{array}{c}\text { Synergy } \\
\text { Index }\end{array}$} \\
\hline & $\begin{array}{c}\text { TRAIL } \\
(-)\end{array}$ & $\begin{array}{l}\text { TRAIL } \\
(+)\end{array}$ & & & $\begin{array}{c}\text { TRAIL } \\
(-)\end{array}$ & $\begin{array}{l}\text { TRAIL } \\
(+)\end{array}$ & & \\
\hline & 1.00 & 0.76 & & & 1.00 & 0.97 & & \\
\hline Origanum majorana & 0.92 & 0.93 & 0.70 & 1.33 & 1.04 & 0.98 & 1.01 & 0.98 \\
\hline Calotropis gigantea & 0.62 & 0.36 & 0.48 & 0.75 & 0.48 & 0.16 & 0.46 & 0.35 \\
\hline Rhus trichocarpa bark & 1.03 & 0.96 & 0.78 & 1.23 & 0.97 & 0.92 & 0.94 & 0.98 \\
\hline Rhus trichocarpa wood & 1.00 & 0.97 & 0.76 & 1.27 & 0.88 & 0.83 & 0.85 & 0.98 \\
\hline Syzygium cumini & 1.04 & 1.15 & 0.79 & 1.46 & 0.73 & 0.69 & 0.70 & 0.98 \\
\hline Artium lappa & 0.91 & 0.83 & 0.70 & 1.20 & 1.14 & 1.16 & 1.10 & 1.05 \\
\hline Rheum austale & 0.65 & 0.65 & 0.50 & 1.31 & 0.68 & 0.69 & 0.66 & 1.05 \\
\hline Nelumbium speciosum & 0.82 & 0.83 & 0.62 & 1.34 & 0.83 & 0.85 & 0.80 & 1.06 \\
\hline Carum copticum & 0.55 & 0.16 & 0.42 & 0.39 & 0.66 & 0.35 & 0.64 & 0.54 \\
\hline Solanum xanthocarpum schrad & 0.25 & 0.30 & 0.19 & 1.56 & 0.10 & 0.11 & 0.10 & 1.09 \\
\hline Vernonia anthelmintica willd & 0.11 & 0.11 & 0.08 & 1.29 & 0.11 & 0.11 & 0.11 & 1.05 \\
\hline Aconitum spicatum & 0.94 & 0.71 & 0.72 & 0.99 & 0.98 & 0.87 & 0.95 & 0.92 \\
\hline Nardostachys grandiflora & 0.07 & 0.07 & 0.05 & 1.31 & 0.08 & 0.08 & 0.08 & 1.01 \\
\hline Delphinium denudatum & 0.96 & 0.81 & 0.73 & 1.10 & 1.11 & 0.96 & 1.07 & 0.89 \\
\hline Kaunia longipetiolata & 0.85 & 0.90 & 0.65 & 1.39 & 0.85 & 0.82 & 0.83 & 0.99 \\
\hline Mucuna nigricans & 0.96 & 0.88 & 0.73 & 1.20 & 1.14 & 1.07 & 1.11 & 0.96 \\
\hline Strychnos nuxvomica & 0.92 & 0.82 & 0.70 & 1.16 & 1.00 & 0.97 & 0.97 & 0.99 \\
\hline Adhatoda vasica Nees & 0.96 & 0.86 & 0.74 & 1.16 & 1.03 & 0.92 & 1.00 & 0.92 \\
\hline Wrightia tinctoria & 0.76 & 0.70 & 0.58 & 1.21 & 0.76 & 0.54 & 0.74 & 0.73 \\
\hline Symplocos racemosa & 0.88 & 0.96 & 0.67 & 1.44 & 0.91 & 0.87 & 0.88 & 0.99 \\
\hline Piper chabo & 0.68 & 0.17 & 0.52 & 0.32 & 0.38 & 0.15 & 0.37 & 0.42 \\
\hline Paris poyphilla & 0.25 & 0.24 & 0.19 & 1.21 & 0.10 & 0.09 & 0.09 & 1.00 \\
\hline Withania somnifera & 1.01 & 1.04 & 0.77 & 1.35 & 1.01 & 0.89 & 0.98 & 0.91 \\
\hline Linum usitatissimum & 0.96 & 0.87 & 0.73 & 1.20 & 0.98 & 1.00 & 0.95 & 1.05 \\
\hline Rhododendron anthopogon & 0.82 & 0.68 & 0.63 & 1.08 & 0.70 & 0.62 & 0.68 & 0.91 \\
\hline Inula cappade & 0.96 & 0.94 & 0.73 & 1.29 & 0.89 & 0.92 & 0.86 & 1.06 \\
\hline Citrullus colocynthis & 0.99 & 0.83 & 0.75 & 1.11 & 0.85 & 0.88 & 0.82 & 1.08 \\
\hline Calotropis gigantean & 0.88 & 0.94 & 0.67 & 1.39 & 0.95 & 0.87 & 0.92 & 0.95 \\
\hline Lyonia ovalifolia & 0.99 & 1.10 & 0.75 & 1.47 & 1.13 & 1.22 & 1.10 & 1.11 \\
\hline Periploca calophylla & 0.93 & 1.04 & 0.71 & 1.46 & 1.31 & 1.41 & 1.27 & 1.11 \\
\hline Zanthoxylum armatum & 0.92 & 1.02 & 0.70 & 1.44 & 1.56 & 1.40 & 1.52 & 0.92 \\
\hline Unidentified & 1.02 & 1.10 & 0.78 & 1.42 & 1.59 & 1.51 & 1.55 & 0.97 \\
\hline Achyranthus aspera & 0.96 & 1.03 & 0.73 & 1.40 & 1.54 & 1.47 & 1.49 & 0.99 \\
\hline Woodforidia fruticos $a^{\mathrm{a}}$ & 0.68 & 0.67 & 0.52 & 1.31 & 0.86 & 0.89 & 0.84 & 1.06 \\
\hline Ficus lacor & 0.91 & 0.97 & 0.70 & 1.40 & 1.35 & 1.36 & 1.31 & 1.04 \\
\hline Paris polyphylla & 0.63 & 0.70 & 0.48 & 1.45 & 0.42 & 0.47 & 0.41 & 1.15 \\
\hline Solanum xanthocarpum & 0.28 & 0.32 & 0.22 & 1.50 & 0.37 & 0.32 & 0.36 & 0.91 \\
\hline Equisetum debile & 1.06 & 1.07 & 0.81 & 1.32 & 1.00 & 0.86 & 0.98 & 0.89 \\
\hline Pogostemon benghalensis & 0.91 & 1.03 & 0.69 & 1.48 & 1.13 & 1.15 & 1.10 & 1.05 \\
\hline Girardiana heterophylla & 0.94 & 0.85 & 0.72 & 1.19 & 1.04 & 0.99 & 1.01 & 0.97 \\
\hline Gaultheria fragrantisia & 0.98 & 0.92 & 0.75 & 1.23 & 1.07 & 1.07 & 1.04 & 1.03 \\
\hline Crateva unilocularis & 1.00 & 1.04 & 0.76 & 1.37 & 1.23 & 1.24 & 1.20 & 1.04 \\
\hline Rabdosia rugosa & 0.99 & 1.00 & 0.75 & 1.33 & 1.13 & 1.21 & 1.09 & 1.11 \\
\hline Curcuma amada & 0.97 & 0.87 & 0.74 & 1.18 & 0.78 & 0.62 & 0.76 & 0.82 \\
\hline Rhododendron anthopogon & 0.82 & 0.87 & 0.62 & 1.40 & 0.90 & 0.87 & 0.87 & 1.00 \\
\hline
\end{tabular}

${ }^{a}$ These plants were collected under different circumstances as regards the time and place. 

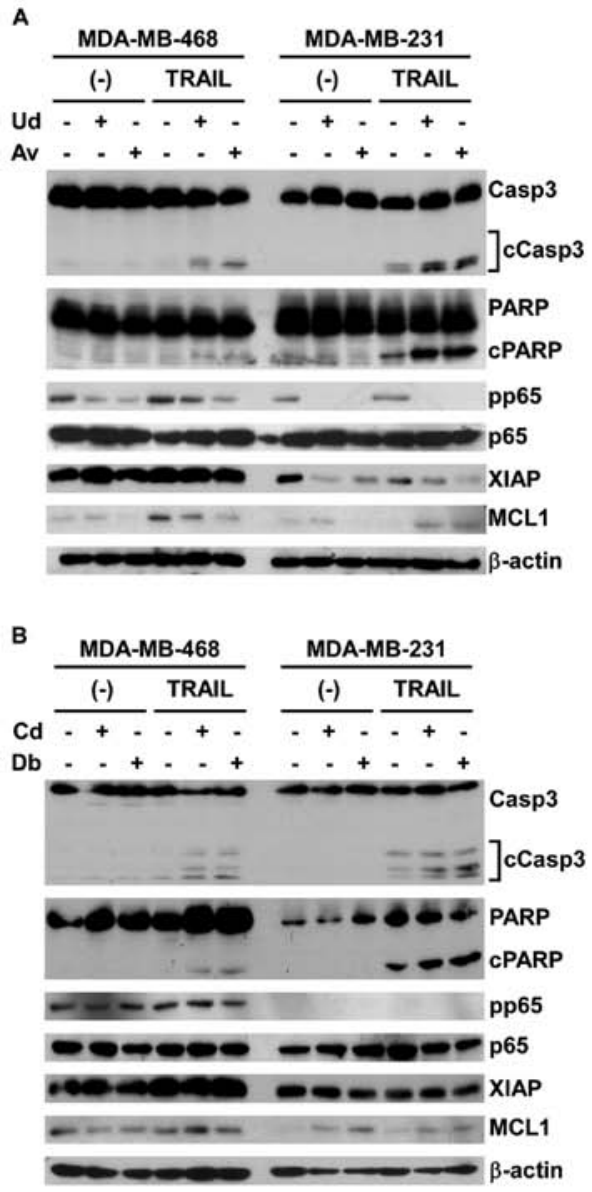

C

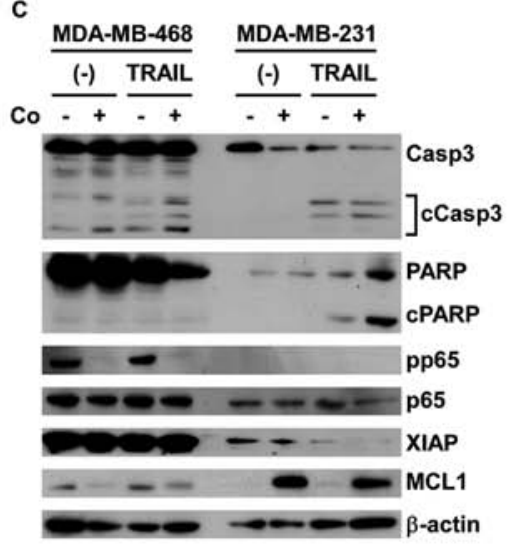

Figure 4. Synergistic effect of the identified medicinal plant extracts on the TRAIL-induced apoptosis. (A-C) Expression of various proteins was detected by western blot analysis in breast cancer cells treated with plant extracts $(50 \mu \mathrm{g} / \mathrm{ml})$ and TRAIL $(50 \mathrm{ng} / \mathrm{ml})$. Ud, U. dac; Av, A. vulgaris; $\mathrm{CD}, C$. depressa; Db, D. bengalensis; Co, C. obtusifolium.

\section{Discussion}

In the present study, we screened 138 medicinal plant extracts for their ability to potentiate TRAIL effects in TRAIL-sensitive cells and to overcome resistant mechanisms in TRAILinsensitive cells. From the screening, 5 potential medicinal plant extracts were identified to sensitize TNBC cancer cells to TRAIL. For identification, we used only two distinct criteria: whether the plant extract displays only minimal toxicity $(<20 \%$ at $50 \mu \mathrm{g} / \mathrm{ml}$ concentration) and whether the extract potentiates
TRAIL-induced cell death in a synergistic manner. Our results demonstrated that these two criteria suffice to identify extracts as TRAIL-sensitizing reagents. This screening criteria can also be applied for drugs other than TRAIL to identify drugsensitizing reagents.

Although we only focused on plant extracts showing low cytotoxicity and synergistic effects with TRAIL in both cells, the screening results in Fig. 2 and Table I provide significant insight into the cytotoxic activity of each plant extract as well as their combination effects with TRAIL. Eight plant extracts (C. obtusa, S. dulsis, O. valgatum, O. indicum, L. sativus, C. gigantean, C. copticum and P. chabo) showed cytotoxicity and synergistic effects in both cell lines (Fig. 2). In addition, 38 plant extracts (including $S$. anacardium, $C$. caesia, E. royleana) revealed strong cytotoxicity with or without TRAIL in both cell lines (Table I); therefore, the active constituents present in these extracts need further investigation as potential chemotherapeutic agents against breast cancer. The extracts of $C$.fructus, $C$. japonica, A. venustum and P. benghalensis showed low cytotoxicity with synergistic effects with TRAIL in MDA-MB-231 cells but showed cytotoxicity and synergistic effects in MDA-MB-468 cells. Therefore, further study of these extracts may provide critical information and clues to identify TRAIL-resistant mechanisms that are specifically active in MDA-MB-468 cells.

Among the 5 plant extracts sensitizing breast cancer cells to TRAIL, $U . d a c$ and its active constituent $(+)$ grandifloracin showed anti-austerity activity against PANC-1 human pancreatic cancer cells in a nutrition-deficient tumor-mimicking environment (18). The extract of $A$. vulgaris has been reported to have cytotoxicity against MCF-7 cells (19). Consistent with these findings, $U$. dac and A. vulgaris also showed cytotoxicity at higher concentrations (Fig. 3A and B) in the present study, although we used lower non-cytotoxic concentrations to identify the synergistic effects with TRAIL. The possible mechanisms of sensitization by the newly identified plant extracts to TRAIL-induced cell death of TNBC were investigated by western blot analysis (Fig. 4). In particular, U. dac, A. vulgaris and $C$. obtusifolium may sensitize breast cancer cells via suppression of the phosphorylation of p65, which is involved in the resistant mechanism to TRAIL (9); however, further investigation of the other two extracts, $C$. depress $a$ and $D$. bengalensis, is necessary to understand the mechanism of action of these extracts.

In conclusion, the results of this study provide valuable information about potential medicinal plants that could enhance TRAIL activity and develop combination therapies against breast cancer. The 5 medicinal plant extracts identified in the present study were unique, as they enhanced the sensitivity to TRAIL in both TRAIL-sensitive and -insensitive TNBC cells. Furthermore, these extracts could have potential medical applications to improve TRAIL efficacy and to overcome resistance mechanisms not only in breast cancer, but in other types of cancer as well.

\section{Acknowledgements}

We thank Professor Hiroaki Sakurai (Faculty of Pharmaceutical Sciences, University of Toyama, Japan) for helpful discussions. 


\section{References}

1. Jemal A, Bray F, Center MM, Ferlay J, Ward E and Forman D: Global Cancer Statistics. CA Cancer J Clin 61: 69-90, 2011.

2. Brenton JD, Carey LA, Ahmed AA and Caldas C: Molecular classification and molecular forecasting of breast cancer: ready for clinical application? J Clin Oncol 23: 7350-7360, 2005.

3. Hudis CA and Gianni L: Triple-Negative Breast Cancer: An Unmet Medical Need. Oncologist 16: 1-11, 2011.

4. Haffty BG, Yang Q, Reiss M, et al: Locoregional relapse and distant metastasis in conservatively managed triple negative early-stage breast cancer. J Clin Oncol 24: 5652-5657, 2006.

5. Dent R, Trudeau M, Pritchard KI, et al: Triple-negative breast cancer: clinical features and patterns of recurrence. Clin Cancer Res 13: 4429-4434, 2007.

6. Keane MM, Ettenberg SA, Nau MM, Russell EK and Lipkowitz S: Chemotherapy augments TRAIL induced apoptosis in breast cell lines. Cancer Res 59: 734-741, 1999.

7. Chinnaiyan AM, Prasad U, Shankar S, et al: Combined effect of tumor necrosis factor-related apoptosis-inducing ligand and ionizing radiation in breast cancer therapy. Proc Natl Acad Sci USA 97: 1754-1759, 2000.

8. Walczak H, Miller RE, Ariail K, et al: Tumoricidal activity of tumor necrosis factor-related apoptosis-inducing ligand in vivo. Nat Med 5: 157-163, 1999.

9. Lirdprapamongkol K, Sakurai H, Suzuki S, et al: Vanillin enhances TRAIL-induced apoptosis in cancer cells through inhibition of NF- $\mathrm{KB}$ activation. In Vivo 24: 501-506, 2010.

10. Lirdprapamongkol K, Sakurai H, Kawasaki N, et al: Vanillin suppresses in vitro invasion and in vivo metastasis of mouse breast cancer cells. Eur J Pharm Sci 25: 57-65, 2005.

11. Choo MK, Kawasaki N, Singhirunnusorn P, et al: Blockade of transforming growth factor-beta-activated kinase 1 activity enhances TRAIL-induced apoptosis through activation of a caspase cascade. Mol Cancer Ther 5: 2970-2976, 2006.
12. Falschlehner $\mathrm{C}$, Emmerich $\mathrm{CH}$, Gerlach $\mathrm{B}$ and Walczak $\mathrm{H}$ : TRAIL signalling: decisions between life and death. Int $\mathrm{J}$ Biochem Cell Biol 39: 1462-1475, 2007.

13. Burns TF and El-Deiry WS: Identification of inhibitors of TRAIL-induced death (ITIDs) in the TRAIL-sensitive colon carcinoma cell line SW480 using a genetic approach. J Biol Chem 276: 37879-37886, 2001.

14. Clohessy JG, Zhuang J, de Boer J, Gil-Gómez G and Brady HJ: Mcl-1 interacts with truncated Bid and inhibits its induction of cytochrome $\mathrm{c}$ release and its role in receptor-mediated apoptosis. J Biol Chem 281: 5750-5759, 2006.

15. Chawla-Sarkar M, Bae SI, Reu FJ, Jacobs BS, Lindner DJ and Borden EC: Downregulation of Bcl-2, FLIP or IAPs (XIAP and survivin) by siRNAs sensitizes resistant melanoma cells to Apo2L/TRAIL-induced apoptosis. Cell Death Differ 11: 915-923, 2004.

16. Ravi R and Bedi A: Potential methods to circumvent blocks in apoptosis in lymphomas. Curr Opin Oncol 14: 490-503, 2002.

17. Shrader M, Pino MS, Lashinger L, Bar-Eli M, Adam L, Dinney CP and McConkey DJ: Gefitinib reverses TRAIL resistance in human bladder cancer cell lines via inhibition of AKT-mediated $\mathrm{X}$-linked inhibitor of apoptosis protein expression. Cancer Res 67: 1430-1435, 2007.

18. Awale S, Ueda J, Athikomkulchai S, Abdelhamed S, Yokoyama S, Saiki I and Miyatake R: Antiausterity agents from Uvaria dac and their preferential cytotoxic activity against human pancreatic cancer cell lines in a nutrient-deprived condition. J Nat Prod 75: 1177-1183, 2012.

19. Taghizadeh Rabe SZ, Mahmoudi M, Ahi A and Emami SA: Antiproliferative effects of extracts from Iranian Artemisia species on cancer cell lines. Pharm Biol 49: 962-969, 2011. 